EMBRYARIDDLE
Aeronautical University

SCHOLARLY COMMONS

\section{International Journal of Aviation,} Aeronautics, and Aerospace

\title{
Flight Surgeons, Aerospace Medicine And NATO Aeromedical Doctrine: Where Is The Alliance For Flight Safety?
}

\author{
Jacopo Frassini \\ NATO Centre of Excellence for Military Medicine, interop.doctrine2@coemed.org \\ Zoltán Tóth \\ NATO Centre of Excellence for Military Medicine, interop.doctrine@coemed.org \\ Petr Král \\ NATO Centre of Excellence for Military Medicine, interop@coemed.org
}

Follow this and additional works at: https://commons.erau.edu/ijaaa

\section{Scholarly Commons Citation}

Frassini, J., Tóth, Z., \& Král, P. (2020). Flight Surgeons, Aerospace Medicine And NATO Aeromedical Doctrine: Where Is The Alliance For Flight Safety?. International Journal of Aviation, Aeronautics, and Aerospace, 7(4). https://doi.org/10.15394/ijaaa.2020.1541

This Position Paper is brought to you for free and open access by the Journals at Scholarly Commons. It has been accepted for inclusion in International Journal of Aviation, Aeronautics, and Aerospace by an authorized administrator of Scholarly Commons. For more information, please contact commons@erau.edu. 
In 2020, the North Atlantic Treaty Organization (NATO) reached 30 member States, a family that now gathers almost a billion people in two continents. The strength of being an always-evolving Alliance grants a significant advantage to collective security but also poses new challenges to the interoperability of the individual national military systems to achieve synergy when acting together.

The NATO Centre of Excellence for Military Medicine is an international military organization committed to facilitating the dialogue among the Allies to continuously improve quality in multinational healthcare systems and supporting the transformation of the Alliance in the accomplishment of medical effectiveness for the success of NATO mission and tasks. Despite NATO doctrine and international standards in aviation are widely agreed, the implementation of practices for aeromedical quality and safety is still left to the initiative of each country. Different sensibilities and backgrounds within the Alliance frequently lead to different processes and uneven results, especially when common educational initiatives for such a demanded medical workforce are difficult to sustain.

The purpose of this paper is to describe the complex role of flight surgeons in NATO beyond their mostly known function of occupational medicine providers in the assessment of pilots. This paper is believed to serve as an easily accessible overview of NATO aeromedical doctrine to help flight surgeons, policy makers and other stakeholders grow a common understanding of the core responsibilities of flight surgeons in the Alliance when requested to deliver best practice in Aerospace Medicine independently from their national lineage.

\section{Core Requirements for Flight Surgeons in NATO}

Flight Surgeons (FS) are physicians who are officially recognized in NATO because of their special training in aerospace medicine(NATO, 2020a). The term "flight surgeon" has been historically reserved to appoint physicians specifically assigned to an air command or space agency where they are responsible for the maintenance of aeromedical safety in air/space operations and are entitled to provide continuous medical support to allocated personnel.

To be considered FSs, medical officers with a nationally recognized qualification in medicine are selected by their national authorities to receive a special curriculum in aerospace medicine and are trained to:

- $\quad$ Manage the aeromedical risk following national/international regulations, policy documents, clinical recommendations, agreed standards of care and best practices(ICAO, 2012; NATO, 2017, 2019b, 2020a)

- Perform their specific duties in the air and space environments(NATO, 2016d, 2019b)

- $\quad$ Advise and cooperate with other elements of the command structure in order to promote aviation safety governance, including preparation to respond to aircraft incidents and accidents(NATO, 2018f, 2019b) 
International regulations in civil aviation globally identify a class of private physicians, known as Aviation Medical Examiners (AMEs), who are designated by relevant aviation authorities (i.e. Federal Aviation Authority) to perform medical assessments of flight crews in the process of establishing and issuing evidence which guarantees that the applicant/holder of an aviation license meets the International Civil Aviation Organization (ICAO) medical requirements for flight duties. The principle behind periodic medical assessments, which applies to civilian and military flight crews indistinctly, is to certify that applicants show no physical or mental condition which may reduce their medical fitness to significant degree until the next scheduled renewal. Inflight incapacitation is the key hazard to be medically evaluated so that the overall risk of incapacitation in aviation should be kept below a commonly accepted threshold (ICAO, 2012).

Starting from this internationally agreed civilian approach, NATO policies on medical support impose additional standards of assistance that should be offered to a fighting force (NATO, 2018e), basically reflecting the traditional role of FSs as military medical officers and specialized active parts of a wider Force Health Protection system. This implies that the physical and psychological integrity of flight crews and ground teams is continuously monitored and safeguarded for a successful flight mission preparation, sustainment, accomplishment and conclusion (NATO, 2016d).

Inevitably, FSs need to achieve the deepest awareness of their military environment by sharing values, traditions, objectives and tasks to accomplish mission success. Operational military communities are generally selected young populations. Typically, behavioral factors under 40 years of age are at the same time more common than physical disease and more difficult to assess during a single periodic encounter with a medical practitioner. Even highly selected, resilient, and trained individuals are no exception to the consideration that should be maintained on their medical readiness and fitness, especially when their workload is aggravated by harsh operational conditions (combat tempo, mission tasks, deployed settings, environmental stress...) (NATO, 2020b).

Differently from AMEs in civil aviation, who may lack the structures to provide continuity in healthcare, FSs have the advantage to be integral components of these communities. Air commands are learning systems where flight crews are the only real-time sensor of human factors and are trained to report medical events of any kind to FSs who are the medical authority responsible to assess the relevance of these events for flight safety. Periodic medical examinations represent only a formal appointment with the FS where a comprehensive assessment is not limited to the physical checkup of the day but is complemented by a deeper understanding of the individual over time. This privileged connection is supported by confidentiality and is effective only when respective roles, responsibilities and limitations are clearly acknowledged (NATO, 2019a).

The clinical approach to aeromedical safety must also be disciplined and harmonized with other elements of the command structure who are generally 
the final executive bodies in the overall risk management of air missions while the importance of upholding the ethical boundaries of a trusted medical practice must be simultaneously supported and recognized (NATO, 2018e, 2019a).

\section{Flight Safety and Aeromedical Governance}

Safety in NATO is a condition intended to prevent injury and damage, or at least a state in which the risks of harm are reduced and controlled to an acceptable level (NATOTerm, n.d.). In Allied operations, flight safety is the result of an interdisciplinary learning process that guides leaders at all levels of command in their risk management strategy better known as the Flight Safety Program (NATO, 2018a). The success a Flight Safety Program is based on a trusted reporting system from flying units to decision makers concerning all issues that might have endangered the mission and can contribute to maintain risk awareness adherent to evolving combat conditions.

Information needs to be shared from originators to higher formations so that the overall picture can be analyzed for wider applications. Remedial actions are then generated in order to avoid the repetition of adverse occurrences. Aerospace medicine is the specialty of medicine concerning the determination and maintenance of the health, safety, and performance of those who fly or control systems in the air and space environments (NATO, 2016d). This definition implies two essential tasks to FSs in their contribution to flight safety:

Fitness for Flight Duty (FFD) (NATO, 2016d, 2017, 2018b) - to protect aircrews and ground teams. It represents the overall requirement to fly for aircrews and to control missions for ground teams. Fitness is assisted by healthcare support initiatives of FSs (preventive, diagnostic, therapeutic, administrative...)

Fitness for Air Travel (FAT) (NATO, 2016d, 2019a, 2020a) - to protect patients. It is specific of air transport of people. Patients selected for aeromedical evacuation must be cleared for the proposed flight balancing fitness considerations against the potential negative influence of the cabin environment on the clinical conditions of the patients.

Such medical responsibilities certainly overlap with the duties of the Air Commanders in the common area of risk management related to human factors (Figure 1). 


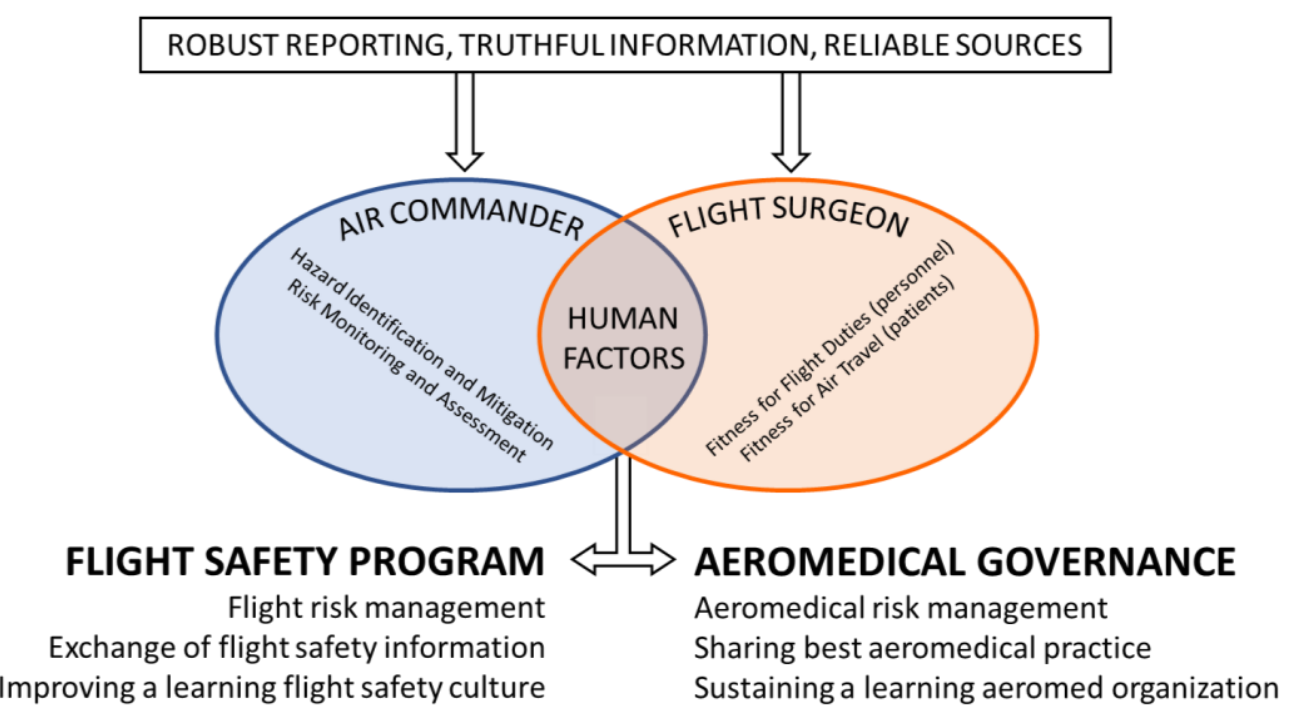

Figure 1. Interaction between the role of Air Commanders and FSs in risk management for flight safety.

Human factors account as one of the most prevalent causes of adverse occurrences in aviation and are increasingly likely with the growing complexity of the system and operational stressors (Wiegmann \& Shappell, 2003). Threats to safety and errors can be subject to preventive measures that enhance early identification and corrective actions so that vulnerable situations do not necessarily end in accidents (NATO, 2018a). Multinational medical support solutions are also exposed to interoperability gaps among different Allies that may amplify the risk of adverse events if not collectively monitored and corrected. A system of aeromedical governance that sets the rules and responsibilities to the medical community (NATO, 2016d, 2018e, 2019a), similarly to a Flight Safety Program, is required to accomplish the agreed allied standards of care in air and space operations, and achieve best outcomes on aeromedical support quality and safety (Frassini, 2020).

\section{Aeromedical Governance in the Aerospace Medicine Construct}

NATO doctrine in aerospace medicine addresses overarching concepts that have the primary objective of harmonizing national approaches to the provision of aeromedical standards in allied settings (NATO, 2016d).

According to the Aerospace Medical Association (AsMA) (Aerospace Medical Association, n.d.), aerospace medicine has four domains of practice where the two tasks of FSs (FFD+FFA) are executed:

- the Clinical Domain,

- the Operational Domain,

- the Scientific Domain and

- the Education \& Training Domain 
The general framework of the four domains in an allied environment is depicted in Figure 2.

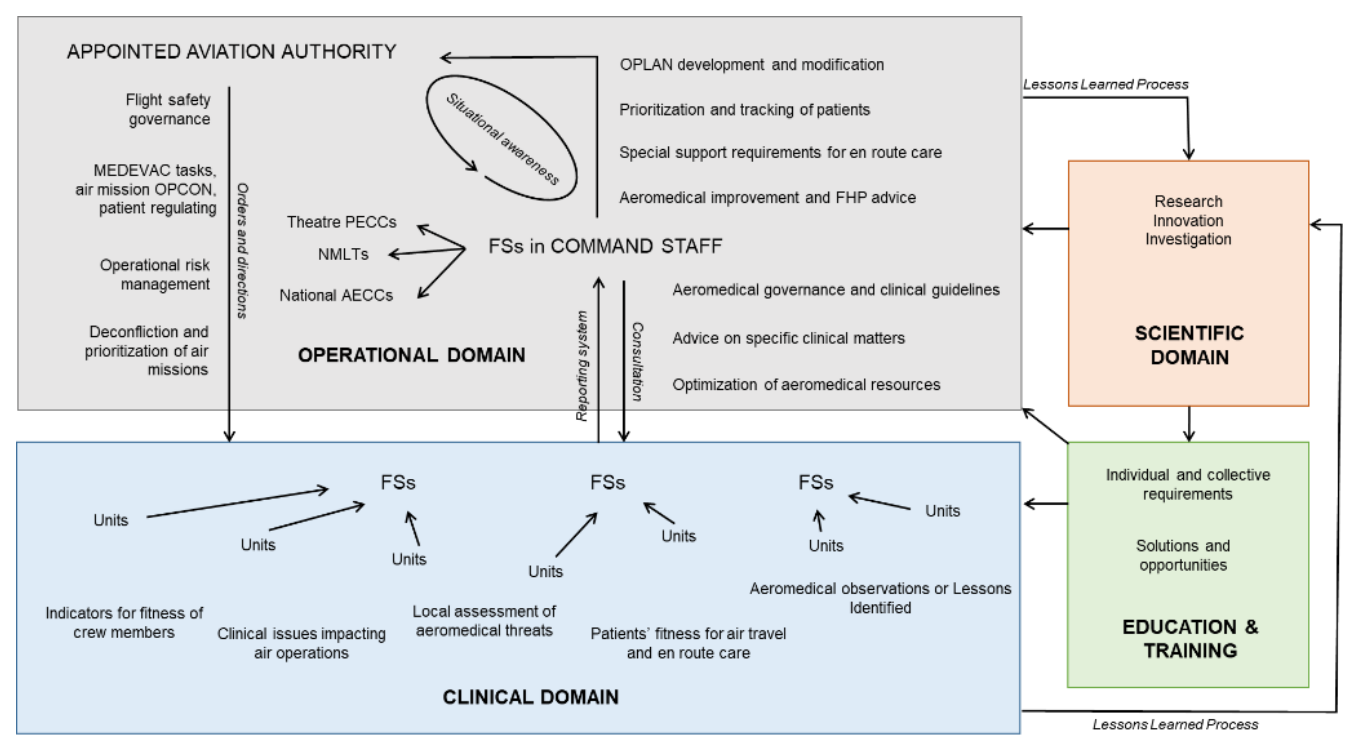

Figure 2. The more relevant functions and connections of the four domains of aerospace medicine that enable medical support to allied air operations. FS: Flight Surgeon. PECC: Patient Evacuation Coordination Cell. NMLT: National Medical Liaison Team. AECC: Aeromedical Evacuation Coordination Centre. OPLAN: Operations Plan. OPCON: Operational Control. FHP: Force Health Protection.

The connections of FSs are more specifically addressed during the planning process of individual operations. Essentially, professional relationships follow a functional network that leverages the principles of leadership, management and governance of the classical military organizations to react quickly, concentrate efforts and achieve advantage from opportunities. Leadership aligns the medical vision to the mission objectives, management ensures efficiency and effectiveness in the use of resources while governance identifies roles, rules and responsibilities (MSH, 2017).

The Clinical Domain refers to the most tactical level of aeromedical support where FSs are directly engaged in delivering healthcare measures. In NATO operations, health is the ability to carry out duties unimpeded by physical or psychological problems (NATO, 2018e). Achievements in interoperability of military aerospace medicine among NATO countries are substantial (i.e. crosslicensing and credentialing of multinational medical practitioners). The Allies agree on the high international standardization and value of the aeromedical curriculum of each contributor and mutually recognize the delivery of the whole spectrum of primary care, the provision of periodic flight physical examinations 
in accordance with the FS's national medical regulations and the issuing of temporary duty/service limitations (grounding/ungrounding) of crewmembers (NATO, 2017, 2018b). Clinical practice of FSs is not limited to flight crews but they can also be directly involved in the pre-flight assessment of patients and in their support during aeromedical evacuation (AE) on military platforms. NATO doctrine recognizes two forms of AE teams for high-dependency patients: the Critical Care Air Support Team (CCAST) and the Medical Emergency Response Team (MERT) (NATO, 2016a, 2016b). They are physician-led teams of doctors, nurses and technicians (mostly providers with background in critical/intensive care, anesthesiology and emergency medicine) trained by the Air Force. Originally, the US version of the NATO CCAST, named CCATT (Critical Care Air Transport Team), was designed to operate within the tactical and strategic aeromedical evacuation phases whereas the native UK solution of MERT to enhance the pre-hospital life support interventions in the forward area. CCAST and MERT are now functions of the allied continuum of care and are intended to provide a same or higher level of medical support compared to what is available before handover of patients (NATO, 2018d, 2019a).

The Operational Domain focuses on the benefits of a task-oriented management of health threats to a community by advice to the chain of command in the planning and in the conduct of operations (NATO, 2016d). Best clinical outcomes are achieved only if high quality care is provided directly to patients. Thus, FSs should be assigned as close to air units as possible. However, health protection is not an exclusive task of FSs, but a consequence of the supporting activity carried out with the tools of coordination of resources on a wider scale (NATO, 2018c). The contribution of aerospace medicine to the prioritization of efforts and to the optimization of outcomes is an oftenneglected portion of increasing importance for aeromedical safety and quality. In order to achieve effective integration of aeromedical requirements in the decision-making process of the headquarters, only few FSs are needed. Their main role will be to anticipate the vulnerabilities of the tactical level and synchronize all measures in order to maximize the timely provision of the right capability to the fighting force. Under all circumstances, Nations remain the risk owners for their force (NATO, 2018e). Nations are clearly responsible for the flight safety services offered to the international community, but it is quite questionable if these services can accomplish air missions without a real multinational platform. And this is where NATO must take over the responsibility to deliver aeromedical governance for a continuous improvement of healthcare support on combined-joint operations (CIHSO) (Frassini, 2020; NATO, 2016d, 2018e, 2019a). The organization of an aerospace medicine service in the Alliance starts well in advance, from the development of an agreed network of FSs at all levels of medical support that results in interoperable clinical outputs and measurable benefits on aeromedical performance (NATO, 2018a). This network relies on high-quality medical practice and leadership to be effective and adaptable. Exploiting the principles of aeromedical 
governance, the Operational Domain enables the clinical awareness of the battlespace to be translated in medically effective decisions of air commanders.

The Scientific Domain: The very first lesson FSs learn in any Air Force service of the Alliance is that air operations must be effective, sustainable and safe. According to the NATOTerm database, flight safety is "the state in which risks associated with flight activities, as well as those related to, or in direct support of the operation of the aircraft, are reduced and controlled to an accepted level" (NATOTerm, 2020). It represents a paramount responsibility to aviators of all levels who are the main sensors of a constantly learning and improving system(NATO, 2018a). When FSs are engaged in research initiatives they generally contribute with medical knowledge in multidisciplinary teams made up by engineers, physics, chemists, pilots, managers, legal advisors and other aviation experts. Research involves all aspects of aerospace medicine required to validate evidence-based best practices from the assessment of occupational and environmental risk factors to the anticipation of medical requirements for air and space operations. According to the report on "Passenger casualty rates for different modes of travel" (UK Government, 2020), air travel in 2020 is still believed to be the safest long-range means of transport compared to road vehicles, trains and ships considering the number of fatalities per distance traveled. Such an accomplishment is the result of advanced applied standards in aerospace research involved in new technologies, materials, procedures, policies and human performance that frequently derives from cutting-edge military experience. Despite most of these activities are conducted individually by the Allies, NATO platforms such as the NATO Standardization Boards, Working Groups and Panels and the NATO Science and Technology Organization can provide a collective environment where to share, harmonize and disseminate knowledge in support of the core medical functions of the Alliance (NATO, 2018e). Additionally, in order to facilitate the generation of comparable information between nations, NATO has designed a standardized approach to identify and analyze hazards in mishaps by setting a common aeromedical approach to incidents and aircraft accidents (NATO, 2018f). In such circumstances an Aircraft Accident and Incident Investigation Board is established, and a FS is included in the panel. Human factors are accounted for being implicated in most fatal and non-fatal mishaps in either military or civilian settings (Wiegmann \& Shappell, 2003). Therefore, FSs may be involved in that area of investigation most likely to generate results or at least to be source of observations for future recommendations. FSs have also an extremely difficult task in understanding the role of human factors in the complex interaction with highly technological machines and explore unprecedented scenarios that lead to certain outcomes. Over the past decades, the effectiveness of all research initiatives in aeromedical science translated in constantly decreasing mortality rates in aviation (B3A, 2020; Wiegmann \& Shappell, 2003).

Education \& Training Domain: In NATO, education, training, evaluation and exercise (ETEE) are considered core functions for the 
maintenance of a military capability to prevent war, to provide effective defense within NATO tasks and to engage partners with appealing cooperative opportunities (NATO, 2014). ETEE activities are regularly coordinated at strategic level to meet the ETEE requirements that are identified and agreed in the allied Global Programming process. Global Programming converts the politico-military guidance and operational needs into NATO ETEE solutions in enough quantity to ensure effectiveness (NATO, 2016c). Specifically, education and training have a very strong national footprint in medicine. Education grows competences that enable individuals to make reasonable responses to unpredictable situations. Training applies to the development of knowledge and skills necessary to perform specific duties and tasks in response to predictable situations. Since November 2019, FSs can rely on an agreed curriculum which defines the minimum allied standard to be considered a FS in NATO (NATO, 2019b). However, when individual professionals enter the multinational dimension of the Alliance, they will need additional training to be able to integrate quickly with the new allied environment involving either practice or operational staffing. Therefore, individual and collective ETEE activities are provided across the NATO network of approved bodies of knowledge and skills to deliver a standardized level of interacting according to their destination in the Alliance. Current opportunities can be consulted on the NATO Education and Training Opportunities Catalogue - ETOC (https://eitep.act.nato.int/Guest/ETOCindex.aspx), but specific medical courses are still rare or still need an official recognition in the NATO portfolio. Emerging areas of interest for allied aeromedical ETEE initiatives include:

- $\quad$ interoperability of multinational AE teams and platforms,

- $\quad$ preparation of future aeromedical leaders in staffing NATO tactical- and operational-level commands,

- $\quad$ solutions for aeromedical governance in medical/non-medical allied exercises, and

- evaluations of aeromedical assets to be validated for multinational allied operations.

Such requirements can be supported by individual nations on a regular basis or can be collectively achieved by NATO providers within the ETEE priorities identified by allied strategic commands(NATO, 2014).

\section{Conclusion}

Flight surgeons in NATO are military medical officers with a central role in supporting quality and safety in air and space operations. On one side, they are an integral part of the military community sharing common values, traditions, objectives and tasks in order to protect the physical and psychological readiness of air crews in a continuous effort to improve flight safety. On the other side, they contribute to the comprehensive understanding of the human interaction with the air and space environments so that preventable medical risks of air/space travels are anticipated and managed. Aerospace medicine is a well- 
standardized discipline and the allied aerospace medical doctrine represents a solid framework where flight surgeons can systematically coordinate their clinical, operational, educational and scientific expertise to achieve best aeromedical outcomes in NATO operations. 


\section{References}

AsMA. (2020). Aerospace Medical Association. https://www.asma.org/aboutasma/careers/aerospace-medicine

B3A. (2020). Statistics of the bureau of aircraft accidents archives. http://www.baaa-acro.com/statistics

Frassini, J. (2020). Continuous improvement in healthcare support on NATO operations. BMJ Military Health. https://doi.org/10.1136/bmjmilitary2020-001543

ICAO. (2012). Manual of civil aviation medicine (3rd ed.). ICAO. https://www.icao.int/publications/documents/8984_cons_en.pdf

MSH. (2017). Leadership management, and governance evidence Compendium. USAID. https://www.usaid.gov/sites/default/ files/documents/1864/LMG_Evidence_Compendium_Introduction_an d_Pharm_chapters-508.pdf

NATO. (2014). MC 0458/3 - NATO education, training, exercises, and evaluation (ETEE) policy.

NATO. (2016a). AMedP-1.7 (Ed.A v.1)—Capability matrix (STANAG 2560). https://www.coemed.org/resources/stanag-search

NATO. (2016b). AMedP-1.8 (Ed.A v.1)—Skills matrix (STANAG 2560). https://www.coemed.org/resources/stanag-search

NATO. (2016c). Bi-SCD-075-002-Education and training directive.

NATO. (2016d). AAMedP-1 (Ed.A v.1)_Aerospace medicine doctorine (STANAG 7212). https://www.coemed.org/resources/stanag-search

NATO. (2017). AAMedP-1.10 (Ed.A v.1) -Interchangeability of NATO aircrew medical categories (STANAG 3526). https://www.coemed.org/resources/stanag-search

NATO. (2018a). AFSP-01 (Ed.B v.1)—Aviation safety (STANAG 7160). https://nso.nato.int/nso/

NATO. (2018b). AAMedP-1.6 (Ed.A v.1)-Temporary flying restrictions due to exogenous factors affecting aircrew efficiency (STANAG 3474). https://www.coemed.org/resources/stanag-search

NATO. (2018c). AJMedP-4 (Ed.A v.1)—Allied joint medical force health protection doctrine (STANAG 2561). https://www.coemed.org/resources/stanag-search

NATO. (2018d). AJMedP-2 (Ed.A v.1)—Allied joint medical doctrine for medical evacuation (STANAG 2546). https://www.coemed.org/resources/stanag-search

NATO. (2018e). MC 326/4-NATO principles and policies for medical support.

NATO. (2018f). AAMedP-1.7 (Ed.B v.1)-Aeromedical aspects of aircraft accident and incident investigation (STANAG 3318). https://www.coemed.org/resources/stanag-search

NATO. (2019a). AJP-4.10 (Ed.C v.1)—Allies joint doctrine for medical support (STANAG 2228). https://www.coemed.org/resources/stanagsearch 
NATO. (2019b). AAMEDP-1.23 (Ed.A v.1)—Minimum requirements for flight surgeon training (STANAG 7231).

https://www.coemed.org/resources/stanag-search

NATO. (2020a). AAMedP-1.1 (Ed.A v.1)—Aeromedical evacuation (STANAG 3204). https://www.coemed.org/resources/stanag-search

NATO. (2020b). AAMedP-1.11 (Ed.A v.1)_Fatigue management in air operations (STANAG 3527).

https://www.coemed.org/resources/stanag-search

NATOTerm. (2020, October 12). NATOTerm online database. https://nso.nato.int/natoterm/Web.mvc

UK Government. (2020, February 12). RAS53-Passenger casualty rates statistics, produced by Department for Transport. https://www.gov.uk/government/statistical-data-sets/ras53-modalcomparisons

Wiegmann, D. A., \& Shappell, S. A. (2003). A human error approach to aviation accident analysis: The human factors analysis and classification system. Ashgate. 